\title{
Research on the Economic Impact of Shandong Expressway Development
}

\author{
GUO Aixin, ZHAO Jinbao, ZHAO Xinhao, ZHOU Meng, KONG Weichao, ZHOU Tianwei \\ School of Transportation and Vehicle Engineering, Shandong University of Technology, Zibo, \\ Shandong 255000, China
}

Keywords: Highways; Economic development; fixed effect model; random effect model; Panel data

\begin{abstract}
By obtaining the panel data of 16prefecture-level cities in Shandong Province from 2005 to 2018 for 14 years, this paper selects Shandong highway mileage as the core explanatory variable, GDP as the explained variable, urbanization rate, passenger volume, freight volume, government participation and fixed capital investment level as other explanatory variables, and adds economic lag effect on this basis. The fixed effect model or random effect model is tested according to the modified Hausman test. In order to make the results more accurate and reliable, the data are tested and corrected by inter-group heteroscedasticity, intra-group autocorrelation, cross-sectional correlation and multiple collinearity, and the spatial effect of Shandong economy is tested by Moran index. In-depth verification of the impact of highway construction on the economy of Shandong Province. The results show that the random effect model has passed the Hausman test. The revised model shows that highway construction has a positive effect on the overall economy of Shandong Province, and other explanatory variables also have varying degrees of pulling effect on the economy, but the spatial effect of economy is not significant, which provides a reference basis and example verification for highway construction in the future. To better promote the close ties between the regions of Shandong Province and make contributions to economic development.
\end{abstract}

\section{Introduction}

Shandong Province connects the Central Plains Economic Zone, and is adjacent to the BeijingTianjin-Hebei and Yangtze River Delta two world-class urban agglomerations from the north to the south. It is a strategic node of my country's expansion from south to north and gradient development from east to west. Taking into account the advantages of land and sea development, it is the northern part of my country. An important open portal occupies a prominent position in my country's regional development strategy in the new era. The construction of expressways in Shandong Province started early. The mileage of expressways in Shandong Province ranked first in the country during the ten years from 1996 to 2005. It is a major expressway province, but its growth rate has slowed down. As of 2020, 15 highways have been completed and opened to traffic in Shandong, and the mileage of expressways has reached 7, 473 kilometers. The proportion of two-way six-lane or more lanes has 
increased from $16 \%$ in 2017 to $26 \%$. In recent years, the growth rate of highway investment has significantly exceeded the national level. . Whether the huge investment in highway construction can also greatly promote the high-quality economic development of Shandong Province remains to be verified.

Jiang Ning used the production function model to analyze the relationship between expressway construction and regional economic development through econometric analysis and found that expressway development has a promoting effect on labor force, capital investment, and the level of urbanization $^{[1]}$. Dong Xiaofang and others used the double difference model to verify the expressway The opening of the highway has a significant positive impact on the economy of the counties passed by $^{[2]}$. In 2013, Wang Chao used a multi-objective explanatory function model in the research on the impact of highway construction on the economic development of Henan Province and found that the economic promotion effect of highway construction is significantly ${ }^{[3]}$, Chen Hua obtained the same result based on the input-output method ${ }^{[4]}$. Zheng Mengmeng found that expressway construction had a significant positive effect on the economic growth of Guangdong Province, and the panel data respectively verified the effect on the overall economy. The contribution of industry, service industry [5], Fan Shifeng used Heze as an example to verify the same conclusion of promoting economic development. In addition, the indirect impact of expressway construction on the regional economy, that is, the promotion of induced benefits and output benefits, was also verified by Dong Yizhe in $2009^{[6]}$. However, some foreign scholars have shown that the construction of highways and other infrastructures cannot promote regional economic growth ${ }^{[7-9]}$.

The exact quantitative relationship between expressway investment and regional development has long been controversial. The spatial dependency of transportation infrastructure and the avoidance of endogenousness, random disturbances between prefecture-level cities, or random disturbances in different periods of the same prefecture-level city are related, The problem of inaccurate empirical results due to the multi-collinearity of various data is often ignored by scholars. Based on these deficiencies, this paper conducts heteroscedasticity, intra-group autocorrelation, cross-sectional correlation, and multicollinearity tests on the data, and uses the modified Hausman test to avoid endogeneity problems leading to negative test results. Research on the economic impact mechanism.

\section{Data source, index selection and model setting}

\subsection{Data source}

The panel data of 16 prefecture-level cities in Shandong Province from 2005 to 2018 are selected in this paper, among which Laiwu City is divided into Jinan City in 2019. All the index data involved are from Shandong Statistical Yearbook, Shandong prefecture-level city statistical yearbook, statistical bulletin, and China Urban Statistical Yearbook. Individual missing value data are filled by the most commonly used method-interpolation.

\subsection{Index selection}

In order to make a more comprehensive analysis of the economic impact mechanism of Shandong expressway development on Shandong Province, this paper selects the following indicators for analysis:

\subsubsection{Core explanatory variable}

The core explanatory variable measures the level of traffic infrastructure by using the expressway mileage, which is the expressway inventory in physical form, and is denoted as ROAD, 
and the unit is kilometer ${ }^{[10]}$.

\subsubsection{Explained variable}

In order to comprehensively analyze the impact of highway development on the economy of Shandong Province, this paper chooses the index to reflect the overall economic development level index GDP (100 million yuan).

\subsubsection{Other explanatory variables}

The construction of expressway will not only make a lasting contribution to the overall economy and optimize the industrial structure, but also include other direct and indirect effects. The direct and indirect effects here are different from those in spatial econometric analysis.

(1) Direct influence

As the highway is a very effective means of financing, it plays an important role in promoting investment in Shandong Province. Secondly, the level of transport infrastructure represents the modernization process of a country or region to a certain extent. The more developed the economy is, the higher the quality of life of the people is, and the faster the process of urbanization is.

(2) Indirect influence

In January 2020, Shandong Province issued the "implementation Plan for implementing the opinions of the CPC Central Committee and the State Council on establishing a more effective New Mechanism for Regional coordinated Development". The plan points out that it is necessary to build a regional development pattern of "one group of two hearts and three circles", that is, "one group", that is, Shandong Peninsula urban agglomeration, and "two hearts", that is, Jinan and Qingdao develop into national central cities. The "three circles" is to promote the integrated development of the three major economic circles of the provincial capital, Jiaodong and southern Shandong. This is also the only way in the process of urbanization of all prefecture-level cities in Shandong Province. In order to realize the development of regional economic integration, one of the most important things is to promote the interconnection of transport infrastructure. The vigorous construction of expressway can be used as a link of regional gridding, change the way of logistics organization, greatly improve transport efficiency, to a certain extent, people have more choices to travel, and provide convenient conditions for close ties between regions.

Based on the above analysis, in order to test whether highway construction is beneficial to all aspects of economic development in Shandong Province, this paper chooses four indicators: the level of urbanization, the level of transportation, the level of fixed capital investment and the degree of government participation as other explanatory variables for empirical research. All specific indicators are defined as shown in Table $1.1^{[11]}$. Among them, the degree of government participation is worthy of the ratio of all government transport expenditure to GDP. The degree of government participation is the ratio of the value of all government transportation fiscal expenditures to the gross domestic product.

Table 1. Definitions of indicators

\begin{tabular}{|c|c|c|c|}
\hline Indicator type & Index selection & $\begin{array}{c}\text { Indicator } \\
\text { representa } \\
\text { tion }\end{array}$ & Index definition \\
\hline $\begin{array}{c}\text { Core explanatory } \\
\text { variables }\end{array}$ & expressway & ROAD & Expressway mileage $(\mathrm{km})$ \\
\hline Explained variable & economic & GDP & Gross Regional Product (100 million \\
\hline
\end{tabular}




\begin{tabular}{|c|c|c|c|}
\hline & development level & & yuan) \\
\hline \multirow{4}{*}{$\begin{array}{c}\text { Other control } \\
\text { variables }\end{array}$} & urbanization level & URBL & $\begin{array}{c}\text { Urban population/year-end permanent } \\
\text { population }\end{array}$ \\
\cline { 2 - 4 } & traffic levels & KY & Passenger volume (ten thousand) \\
\cline { 2 - 4 } & $\begin{array}{c}\text { Government } \\
\text { Involvement }\end{array}$ & GOV & $\begin{array}{c}\text { Gargo volume (10, 000 tons) } \\
\text { Grnment expenditure/gross } \\
\text { domestic product }\end{array}$ \\
\cline { 2 - 4 } & $\begin{array}{c}\text { Fixed capital } \\
\text { investment level }\end{array}$ & IIFA & $\begin{array}{c}\text { Total fixed capital investment/gross } \\
\text { domestic product }\end{array}$ \\
\hline
\end{tabular}

\subsection{Model building}

Panel data (PanelData) is the data obtained in both time and cross-sectional space, which can be called time series cross-sectional data or mixed data. Compared with pure time series and pure crosssectional data, more complex dynamic models can be constructed and verified. The three most commonly used model classifications for panel data are mixed model (Pooledmodel), fixed effect model (fixedeffectsmodel) and random effect model (randomeffectmodel). According to Table 1, based on the original panel data indicators, adding the lag effect of national economic development, the basic equation of the model is constructed as formula 1.

$$
\operatorname{InGDP} P_{i t}=\theta_{1} \operatorname{InROAD}_{i t}+\theta_{2} \operatorname{InGDP}_{i(t-1)}+\sum_{k=3}^{7} \theta_{K} X_{i t}+u_{i}+\varepsilon_{i t}
$$

Among them, it represents the $t$ year of the $i$ prefecture-level city; $I n G D P_{i t}$ is the explained variable, expressed by the logarithmic value of the gross national product; InROAD ${ }_{i t}$ represents the core explanatory variable, that is, the highway mileage of Shandong Province takes the logarithmic value; $\operatorname{InGDP}_{i(t-1)}$ represents the logarithmic value of the economic lag variable; $X_{i t}$ represents the other explanatory variables in Table $1 ; u_{i}$ represents the intercept term of unobservable regional heterogeneity between prefecture-level cities in Shandong Province. $\varepsilon_{i t}$ represents the random disturbance term that varies from year to year; $\theta_{k}$ disturbance represents the regression coefficient of other explanatory variables, and all data are obtained by the software stata16.0.

\subsection{Analysis train of thought}

(1) The fixed effect and random effect of the sorted panel data are analyzed, and then the modified Hausmann test is carried out, and the fixed effect model is selected to return the random effect model.

(2) Check whether there is heteroscedasticity between groups. All the 16 districts and cities in Shandong Province can get their respective variances from the panel data. it is assumed that the variance of Qingdao is not equal to that of Jinan, that is, there is heteroscedasticity between groups, and so on.

$$
\sigma_{\text {qingdao }}^{2}=\operatorname{Var}\left(\varepsilon_{\text {qingdao }}\right) \neq \sigma_{\text {jinan }}^{2}=\operatorname{Var}\left(\varepsilon_{\text {jinan }}\right)
$$

(3) Check to see if there is an intra-group autocorrelation. The data of different periods in a prefecture-level city in Shandong Province is in the group. If the random disturbance items of different prefecture-level cities are related, it means that the index has intra-group autocorrelation. As shown in formula (3), where it represents the $t$ year of the $i$ prefecture-level city.

$$
\operatorname{Cov}\left(\varepsilon_{i t_{1}}, \varepsilon_{i t_{2}}\right) \neq 0\left(t_{1} \neq t_{2}, \forall i\right)
$$


(4) Check whether there is cross-sectional correlation (simultaneous correlation between groups). That is, the correlation of random disturbance items between different prefecture-level cities in the same period. As shown in Formula (4).

$$
\operatorname{Cov}\left(\varepsilon_{i t}, \varepsilon_{j t}\right) \neq 0(i \neq j, \forall t)
$$

(5) Test whether there is spatial spillover effect, and judge according to Moran index. As shown in formula 5, $n$ represents 17 prefecture-level cities; $x_{i}$ represents the GDP value of a prefecturelevel city; $W_{i j}$ is a spatial weight matrix; $I$ represents Moran'I index, and $I$ is closer to 1, indicating that the more obvious the aggregation effect of GDP in Shandong Province is in spatial distribution, the closer to-1, indicating that the divergence in spatial distribution is more significant. Among them, there are many types of spatial weight matrix. in the spatial effect analysis of this paper, $0-1$ matrix is selected as the spatial weight matrix ${ }^{[12]}$.

$$
I=\frac{n \sum_{i=1}^{n} \sum_{j=1}^{n} W_{i j}\left(x_{i}-\bar{x}\right)\left(x_{j}-\bar{x}\right)}{\sum_{i=1}^{n} \sum_{j=1}^{n} W_{i j} \sum_{i=1}^{n}\left(x_{i}-\bar{x}\right)^{2}}
$$

(6) Check whether there is multicollinearity (VIF value). That is, there may be a high correlation between other explanatory variables.

( 7 ) If there are inter-group heteroscedasticity, intra-group autocorrelation and cross-sectional correlation, the fixed and random effect models are modified. The specific process is shown in figure 1.

\section{Verification results and analysis}

In order to avoid the impact of dimensions on the empirical results, we first deal with the logarithm of the index GDP, which represents the overall economic development, as well as passenger and freight volume. The descriptive statistical results of each variable are shown in Table 2.

Among them, there are obvious individual differences among prefecture-level cities in Shandong Province, but individual differences are not considered in the mixed regression model, so they are not shown in Table 3. It should be noted that the statistical caliber of passenger and freight volume has changed after 2014. In order to better explain the actual law of economic changes over time, the data after 2014 are converted according to the growth rate over the years, so that all data caliber is uniform. In order to verify the panel data. All the statistical results are realized by Stata16.0 software.

Table 2 Descriptive Statistics

\begin{tabular}{cccccc}
\hline Variables & $(1)$ & $(2)$ & $(3)$ & $(4)$ & $(5)$ \\
& $\mathrm{N}$ & mean & sd & min & max \\
\hline ROAD & 238 & 5.467 & 0.552 & 3.595 & 6.717 \\
\hline GDP & 238 & 4.488 & 0.96 & 0.11 & 5.472 \\
\hline URBL & 238 & 0.508 & 0.128 & 0.191 & 0.737 \\
InKY & 238 & 9.058 & 0.779 & 7.12 & 10.66 \\
InHY & 238 & 9.596 & 0.925 & 7.316 & 14.44 \\
GOV & 238 & 0.0981 & 0.0286 & 0.0421 & 0.197 \\
IIFA & 238 & 0.633 & 0.147 & 0.335 & 0.974 \\
\hline
\end{tabular}




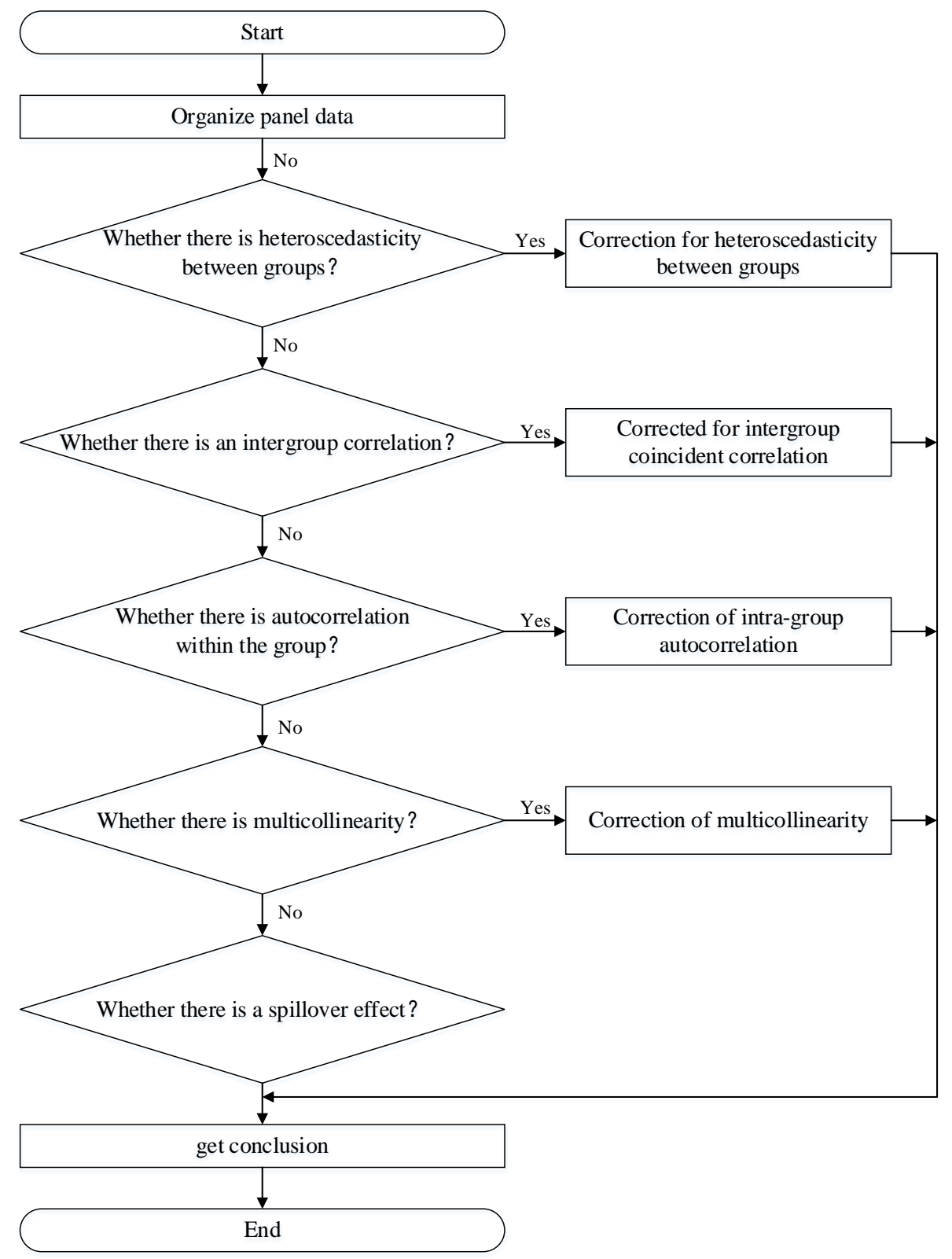

Figure 1. Flow chart of analysis ideas 
In order to avoid the situation that the Hausman test results are negative and can not be analyzed because of the endogenous problems, this paper uses the modified Hausman test and over-recognition test to overcome the above defects according to the practice of Lian Yujun and others ${ }^{[13]}$. According to the test results of Table 3, we can see that the Hausman test result is 0.0497 , which significantly rejects the original hypothesis, so the random effect model is used for analysis. Secondly, the results of inter-group heteroscedasticity, intra-group autocorrelation and cross-sectional correlation test are all less than 0.1, indicating that these three cases exist. The average VIF value is 1.57, which is much less than 10, so there is no multicollinearity in the model. Moran index is a common method to test whether there is a spatial effect ${ }^{[14-16]}$, the result is 0.102 , and the $\mathrm{P}$ value is much greater than 0.1 , indicating that there is no significant spatial spillover effect in the economy of Shandong Province.

Table 3 Statistics of test results

\begin{tabular}{ccccccc}
\hline Type & $\begin{array}{c}\text { Hausman } \\
\text { test }\end{array}$ & Heteroscedasticity & autocorrelation & $\begin{array}{c}\text { Sectional } \\
\text { correlation }\end{array}$ & $\begin{array}{c}\text { Average } \\
\text { VIF value }\end{array}$ & $\begin{array}{c}\text { Moran } \\
\text { index }\end{array}$ \\
\hline result & 0.0497 & 0.00 & 0.00 & 0.02 & 1.57 & 0.102 \\
\hline
\end{tabular}

Then the above analysis modifies the model, and the results before and after the correction are shown in Table 4. It can be seen that the lag effect of the national economy has passed the $1 \%$ significance test before and after the revision, and the future economic development has a lot to do with the previous economic level. Secondly, the regression coefficient of ROAD is positive and significant at $1 \%$ level, indicating that the development of expressways has an obvious positive driving effect on the economic growth of Shandong Province. Every 1\% increase in highway mileage will drive the economic growth of $0.602 \%$.

Capital is the basic element of Solow model, and the economic growth of provinces and cities is inseparable from investment. The output elasticity of fixed capital investment level is $1.578 \%$, and it is significant at $1 \%$ confidence level, that is, a $1 \%$ increase in the proportion of fixed capital investment in GDP of the whole society will boost economic growth by $1.578 \%$. According to the data of Shandong Bureau of Statistics, we can find that fixed capital investment accounts for more than $60 \%$ of GDP, indicating that investment-driven characteristics are more obvious in the process of economic growth in Shandong Province.

The level of urbanization is an important measure of the economic development level of a country or region. The higher the level of urbanization is, the more prosperous the economy is. The verification results also show that every one percentage point increase in the urbanization rate of Shandong Province will boost economic growth by $1.34 \%$. According to population economics, urbanization is the process of transforming agricultural population into urban population, which increases the proportion of industry and service industry, and promotes the optimization and upgrading of industrial structure. Thus indirectly promote economic growth.

Passenger (cargo) transport volume is not only a quantitative index to reflect the service of the transport industry for the national economy and people's life, but also an important index to study the scale and speed of transportation development. The closer the relationship between the regions, the more frequent the logistics exchanges between the two places, the more passengers and goods will be transported. Table 1.3 shows that passenger (cargo) traffic has a positive effect on the economy, but it does not pass the $90 \%$ confidence level test. The possible reason is that this study only studies the passenger (cargo) volume of highway, but does not calculate the number of passengers (goods) transported by water, railway, air and other means, which reduces the pulling force on the economic level to a certain extent. thus, the significance level is reduced, but it is undeniable that the transport level has a positive effect on economic growth.

The regression coefficient of government participation is 10.26 , that is, for every $1 \%$ increase in the 
proportion of government expenditure in the national economy, the economy will grow by $10.26 \%$. Since the Jiqing Expressway was completed and opened to traffic in 1993, the development of expressway in Shandong Province from the initial exploration period to the current period of development transformation is inseparable from the support of government policies. From the medium-and long-term Planning of Shandong Expressway Network (2011-2020) to the medium-and long-term Development Plan of Shandong Comprehensive Transportation Network (2018-2035), the government has continuously increased its financial expenditure on highway construction to 2018. Shandong Province's financial expenditure has reached 1.01 trillion yuan, becoming an important force in promoting economic development.

Table 4 Statistical results of models before and after revision

\begin{tabular}{cccc}
\hline variables & FE & RE & Modified \\
\hline \multirow{2}{*}{ L.Ingdp } & $0.477^{* * *}$ & $0.477^{* * *}$ & $0.2^{* * *}$ \\
& 7.880 & $(7.880)$ & 15.940 \\
\hline \multirow{2}{*}{ ROAD } & 0.132 & 0.132 & $0.602^{* * *}$ \\
& 1.070 & $(1.070)$ & 19.750 \\
\hline \multirow{2}{*}{ IIFA } & 0.385 & 0.385 & $1.578^{* * *}$ \\
& 0.930 & $(0.930)$ & 13.720 \\
\hline \multirow{2}{*}{ URBL } & 0.803 & 0.804 & $1.34^{* * *}$ \\
& 1.520 & $(1.520)$ & 17.240 \\
\hline \multirow{2}{*}{ InKY } & 0.084 & 0.084 & 0.041 \\
& 1.030 & $(1.030)$ & 1.320 \\
\hline \multirow{2}{*}{ InHY } & $(0.039)$ & $(0.039)$ & 0.006 \\
& $(0.560)$ & $(-0.56)$ & 1.140 \\
\hline \multirow{2}{*}{ GOV } & 2.226 & 2.226 & 11.860 \\
\hline \multirow{2}{*}{ Constant } & 0.970 & $(0.970)$ & $-2.16^{* * *}$ \\
& 0.373 & 0.373 & $(6.590)$ \\
\hline
\end{tabular}

Note: ${ }^{* * *} \mathrm{p}<0.01,{ }^{* *} \mathrm{p}<0.05,{ }^{*} \mathrm{p}<0.1$

\section{Conclusions and Suggestions}

According to its own economic development and natural geographical conditions, Shandong Province has put highway construction in the position of the province's transportation priority development strategy. The period from 1998 to 2015 is the stage of rapid development of expressways in Shandong Province, which has greatly promoted economic growth and strengthened the links between regions. In order to make the model test results more reasonable and accurate, the intragroup autocorrelation, intra-group heteroscedasticity, inter-group simultaneous correlation and multicollinearity of the model are tested respectively. The test results show that there is no multiple collinearity in the model. After other existing factors are modified, the panel data model finally adopts the random effect model. The results show that the promoting effect of highway construction on GDP in Shandong Province has passed the significance test of 1\%, that is, for every $1 \%$ increase in highway mileage, the economic growth is $0.602 \%$, and this promoting effect appears when the economy lags behind by one year, which also shows that when the highway mileage increases, the pulling effect on the economic growth of Shandong Province is very rapid. 
Secondly, according to Moran index, the economic spatial effect among prefecture-level cities in Shandong Province is not significant, that is, there is no strong agglomeration effect among prefecture-level cities. The prefecture-level cities with rapid economic development, such as Qingdao and Jinan, do not well promote the economic growth of the surrounding areas, and do not promote the coordinated development of the surrounding cities with slow development.

Other control variables such as the level of urbanization, investment in fixed assets and government expenditure also contribute significantly to the economic growth of Shandong Province. Among them, although the logistics level, that is, passenger and freight volume has a positive promoting effect, it did not pass the $10 \%$ significance test. The possible reason is that Shandong Province has made great efforts to develop "public transfer water and rail" in recent years. A large number of people flow logistics are shared by other modes of transport, resulting in a reduction in the level of significance. According to the results, we can know that speeding up the construction of the transportation network, building the Jiaodong Peninsula on the track, weaving the highway network, and realizing the interconnection between cities at various prefecture levels are the solid foundation for Shandong Province to create a regional development pattern of two hearts and three circles and realize integrated development in the future.

\section{References}

[1] JIANG N. Study on the Relationship between Highway Construction and Regional Economic Development [J]. Fujian Communications Science and Technology, 2019(03):152-154.

[2] DONG X F, LIU Y F. Can the construction of transportation infrastructure drive the development of county economy?_B_Based on the analysis of national highway construction and county-level economic panel data from 2004 to 2013[J].Nankai Economic Research, 2018(04):3- 20.

[3] WANG C. Research on the impact of highway construction on the economic development of Henan Province[D]. Zhengzhou University, 2013.

[4] CHEN H. Research on the impact of expressway on economic development based on the input-output method[J].China Collective Economy, 2015(36):10-11.

[5] ZhENG M M. Empirical analysis of the impact of expressway construction on regional economic development in Guangdong Province[D]. Jinan University, 2017.

[6] DONG Y Z. Research and Application of Post-Evaluation Method for Regional Economic Impact of Expressway Project[D]. Nanjing University of Aeronautics and Astronautics, 2009.

[7] KIM Y L. Spatial Econometric Analysis of Highway and Regional Economy in Missouri[D]. University of MissouriColumbia, 2006.

[8] CANNING D, FAY M. The effects of transportation networks on economic growth[J]. 1993.

[9] FABER B. Trade integration, market size, and industrialization: evidence from China's National Trunk Highway System[J]. The Review of Economic Studies, 2014, 81(3): 1046-1070.

[10] LIU B L, Wu Peng, Liu Yuhai.Transportation Infrastructure and China's Total Factor Productivity Growth-A Spatial Panel Econometric Analysis Based on Provincial Data[J].China Industrial Economy, 2010(3):54-64.

[11] WU R. Research on the impact of highway construction on my country's economic development[D]. Heilongjiang: Harbin Institute of Technology, 2016.

[12] CHEN Q. Advanced Econometrics and Stata Application[M]. Beijing: Higher Education Press, 2013:578-582.

[13] LIAN Y J, WANG W D, YE $R$ C. Monte Carlo simulation analysis of the validity of Hausman test statistics[J].Mathematical Statistics and Management, 2014, 33(05):830-841.

[14] TAO J G, LIU H Y. The agglomeration of strategic emerging industries, spatial spillover effects and the quality of regional economic growth[J].Statistics and Information Forum, 2020, 35(05):26-34.

[15] CHEN J, ZHANG F F, YANG X Y. Research on the spatial spillover of regional entrepreneurship and the effect of economic growth [J]. Science and Technology Progress and Countermeasures, 2020, 37(08):44-50.

[16] YANG L C, HU M Z. Construction of spatial spillover benefit model of economic growth along One Belt And One Road [J]. Journal of Southwest Normal University (Natural Science Edition), 2020, 45(07):107-114. 